\title{
"Bom ou mau docente?" Os desafios entre a teoria e a prática no curso de Pedagogia/IE/UFMT
}

\author{
Viviane Salarolli de Souza Silva \\ Universidade Federal de Mato Grosso - UFMT, Brasil \\ Cleomar Ferreira Gomes \\ Universidade Federal de Mato Grosso - UFMT, Brasil
}

\begin{abstract}
RESUMO
Busca-se compreender o que leva um discente classificar um docente de "bom" ou "mau", traçando assim o perfil do "bom docente". Esclarecer a existência destas categorias nas relações instituídas e suas contribuições para a formação é o que nos move. O estudo foi realizado na Universidade Federal de Mato Grosso, campus Cuiabá/MT. A metodologia foi um questionário de natureza qualitativa. Participaram 20 discentes do curso de Pedagogia matutino $\left(3^{\circ}\right.$ e $4^{\circ}$ anos), sendo 19 do sexo feminino e um do masculino. Com base nos dados, concluímos que a importância não reside na classificação em si, mas, sobretudo, na forma como os educadores optam por um conjunto de características que possibilite o fazer pedagógico e os desafios daqueles que militam pela educação.
\end{abstract}

PALAVRAS-CHAVE: Formação docente. Reflexão. Educação.

\section{"GOOD OR BAD TEACHER?" - THE CHALLENGES BETWEEN THEORY AND PRACTICE IN THE PEDAGOGY COURSE/ IE / UFMT}

\begin{abstract}
It seeks to understand what makes a student classify a teacher as "good" or "bad", thus outlining the "good teacher" profile. Clarifying the existence of these categories in the relations established and their contributions to formation is what moves us. The study was made at the Federal University of Mato Grosso, Cuiabá / MT campus. The methodology was a qualitative questionnaire. Participated 20 students, Pedagogy Course - morning (3rd and 4th years), 19 females and one male. Based on the data, we conclude that the importance lies not in the classification itself, but, overall, in the way that educators choose for a set of characteristics that make possible the pedagogical achievement and the challenges of those who work for education.
\end{abstract}

KEYWORDS: Teacher Training. Reflection. Education.

\section{"BOM O MÁS DOCENTE?" - LOS DESAFÍOS ENTRE LA TEORÍA Y LA PRÁCTICA EN EL CURSO DE PEDAGOGÍA / IE / UFMT}

RESUMEN: Se busca compreender lo que conduce un estudiante a clasificar un profesor como "Bueno" o "malo", se rastreando así el perfil del "bueno profesor". Aclarar la existencia de 
estas categorías en las relaciones instituídas y sus contribuciones para la formación es lo que nos mueve. El studio fue realizado en la Unversidad Federal de Mato Grosso, campus Cuiabá/MT. La metodología fue uno cuestionario de naturaleza cualitativa. Han participado 20 estudiantes, curso de pedagogía - matutino (3o. e 4o. años), 19 del sexo feminino y 01 del masculino. Con base en los dados concluimos que la importancia no reside en la clasificación en sí misma, pero, sobretudo, en la forma como los educadores optan por un conjunto de características que posibilite el hacer pedagógico y los desafíos daquellos que luchan por la educación.

PALABRAS-CLAVE: Formación de profesores. Reflexión. Educación.

\section{INTRODUÇÃO}

O presente estudo tem por intuito compreender o que leva um discente a classificar um docente de bom ou mau professor, traçando assim o perfil do bom professor. Propõe-se ainda a esclarecer a existência destas duas categorias de professores nas relações estabelecidas e construídas entre os sujeitos ao longo do curso, e suas contribuições para a formação de profissionais da educação cada vez mais comprometidos em desenvolver o ser humano, preparando-o para o exercício da cidadania e qualificando-o para o trabalho.

Com abordagem qualitativa, o estudo exploratório e descritivo com o intuito de pesquisar acerca desta temática considera os questionários obtidos dos discentes do curso de Licenciatura Plena em Pedagogia, da Universidade Federal de Mato Grosso (UFMT), do Instituto de Educação (IE), campus Cuiabá/MT, na modalidade presencial, durante os dois primeiros meses do ano de 2016.

\section{A DIDÁTICA E A DOCÊNCIA NO ENSINO SUPERIOR}

A palavra didática vem do grego didaktiké $e^{1} a$ arte de ensinar alguma coisa a alguém. Por isso o sociólogo e filósofo francês Émile Durkheim (2013) vai dizer que a pedagogia é uma mélange, uma mistura entre a ciência e arte. Todo bom professor é, sobretudo, um artista.

O professor do Ensino Superior tem uma tarefa muito difícil nos idos de hoje, pois são recorrentes a falta de maturidade intelectual e a falta de capital cultural - termo utilizado pelo sociólogo francês Pierre Bourdieu (1998) - por parte dos alunos da graduação. Alunos que chegam na graduação com pouca experiência em escrita, com dificuldades, em alguns casos, até para pensar. É fato: o ato de pensar, refletir, não é tarefa das mais fáceis. Pensar assusta o

\footnotetext{
1 A palavra didática vem do grego techné didaktiké, que se pode traduzir como arte ou técnica de ensinar. Disponível em: <http://www.dicionarioinformal.com.br/did\%C3\%A1tico/ > Acesso em: 10 jul. 2016.
} 
próprio pensador. Quando exercitamos esta prática, tornamo-nos mais seletivos, menos preconceituosos e mais tolerantes para aceitar aquilo a que o filósofo francês Jean Jacques Rousseau (2003) se refere quando diz que não temos outro caminho, outro destino, senão tolerar o outro, tolerar o diferente.

Estudos sobre a didática no Ensino Superior nos possibilitam uma reflexão acerca do trabalho docente a ser desenvolvido, para atender a esta nova demanda, a demanda de professores que formarão novos professores. Este trabalho é fruto de estudo e pesquisa analisando o que vem e o que ainda não vem dando certo quanto aos métodos, técnicas, arte de ensinar, de transmitir conhecimento, metodologias, conteúdo e demais estratégias, que possam enfim, conceituar esta palavra que abarca tantos significados - didática.

$\mathrm{Na}$ questão da docência no Ensino Superior, utilizaremos o termo ensinagem, das doutoras em Educação Selma Pimenta e Léa Anastasiou (2005). Elas vão dizer que, para a ensinagem acontecer, é solicitada a participação de um aluno ativo, ou seja, o aluno não pode mais ser um aluno passivo no processo de aprendizagem. As autoras não discutem com profundidade a postura do aluno, o foco delas é discutir a ação do professor, a responsabilidade que ele tem no encaminhamento dessas ações, no que se refere à aprendizagem neste estágio.

Nessa obra (2005), é feita uma sucinta retrospectiva sobre a história da didática, num resgate histórico em que elas afirmam sempre ter havido uma predominância do ensinar sobre o aprender e que, nesse sentido, o foco então não é o aluno, mas é o professor, porque é o professor quem ensina. Então, ele se torna a figura central nesse processo.

Discorrendo sobre essa ideia, as autoras percebem ser isso o fundamento da pedagogia tradicional, em que o professor, sendo o centro do processo, o aluno torna-se o recebedor das informações. Temos a memória sobre a didática muito ligada nessa figura do professor sendo responsável pelo ensinar, e isso elas irão combater ao longo do texto. Se o professor for o centro do processo de ensino-aprendizagem, ao aluno restará um papel muito passivo que, aliás, não se espera do estudante no Ensino Superior.

Segundo Pimenta e Anastasiou (2005), há um crescimento do número de alunos que acessam ao Ensino Superior no Brasil. Apesar disso, tecem algumas críticas ao processo de ensino na universidade; processo de aprendizagem centrado no professor, em que os alunos somente escutam e só o professor fala. O processo de aprendizagem desse aluno é apenas de memorização dos conteúdos que o professor ensinou. Para tanto, o aluno precisa de todos os slides que o professor passou, de todo o material usado na disciplina e essa ideia, na opinião das autoras é fundada na questão de o aluno assistir à aula, de o aluno não faltar às aulas. Muitas vezes, o aluno até sabe o conteúdo, mas não sabe dizer qual a sua aplicação. 
Ainda segundo as autoras, passamos por um longo momento histórico da prescrição metodológica - sempre foi prescrito como é que se faz - a ideia de receitas. Os cursos de formação de professores, em especial, as disciplinas de metodologias de ensino sempre fizeram isso: prescrever como é que se faz.

Pensando no aspecto da diversidade, não é possível adotar um método de ensino idêntico para todos, pois o professor vai deparar com alunos provenientes de realidades diferentes, oriundos de diferentes escolas de Ensino Médio, com diferentes saberes, distintas concepções de um bom professor, de ser aluno... E tudo isso gera um choque.

Estamos vivenciando um momento diferenciado, um processo de mudança; a crença de que exista um único método de ensino idêntico para todos os alunos começa a ser debatida, ou torna-se objeto de discussão nos cursos de formação de professores, seja inicial ou continuada. Os próprios avanços no campo da Didática, que deixa de ser prescritiva para tornar-se mais compartilhada, uma troca de ideias, de experiências... E ao passo em que ocorre essa profissionalização dos professores, refletimos que ser professor não é apenas vocação, é uma profissão; para tanto, faz-se necessária a qualificação.

As autoras (2005) trazem o conceito de ensinar, esclarecendo que faz parte da natureza do ensinar, o compromisso de assegurar que todos aprendam, que o papel da educação é a redução das desigualdades sociais. Houve um crescente processo de escolarização nas sociedades europeias e em outras sociedades, a partir do século XVIII. Esse processo de escolarização que, no $1^{\circ}$ momento, foi para instruir as crianças pequenas que não estavam na tutela dos seus pais, pois estavam trabalhando, todo esse processo vai assumir cada vez mais um caráter humanizado, de formação desse sujeito para a sociedade, de redução das desigualdades, ou de aproximação dessas desigualdades sociais.

A ensinagem, segundo as autoras (2005), carrega consigo um compromisso ético, político e social da atividade docente com os alunos, compromisso esse que se realiza em determinado espaço institucional e, nesse estudo, em função da docência universitária, esse espaço vem ser as universidades, as faculdades, os institutos. $\mathrm{E}$ as pedagogas reiteram que a ação desse professor superior não pode ser desprovida dos pilares do ético, do político, do social.

$\mathrm{O}$ ato de ensinar não se resume, então, ao momento da aula expositiva, encerrado em si mesmo, desconsiderando que a ação de ensinar é conduzida de acordo com os fins educacionais. $\mathrm{O}$ aluno precisa aprender que a aprendizagem é responsabilidade dele, e precisa adquirir, logo, essa autonomia de pensar esse processo. 
As professoras-autoras (2005) definem o conceito de ensinagem, como uma prática social complexa efetivada entre os sujeitos professor-aluno em sala de aula. Esse conceito abrange tanto a ação de ensinar, como a ação de aprender, como uma via de mão dupla, pois o professor ensina, enquanto esse aluno ganha experiência. A dica é que nós, professores, saibamos equilibrar as aulas expositivas e outros momentos de interlocução com nossos alunos.

Por fim, Pimenta e Anastasiou (2005) trazem duas definições para as funções do professor e do aluno. Então qual é a função do professor? Cabe ao professor, realizar as atividades de ensino, de modo que atendam às características do conteúdo, do curso, da disciplina, e principalmente, dos alunos envolvidos no processo. Por esse referencial, serão realizadas atividades na sala de aula e em outros espaços individuais e coletivos, e aqui, as autoras abrem essa possibilidade de o assistir à aula ser uma construção coletiva. E a função do aluno? Cabe ao aluno não ser o sujeito passivo que assiste às aulas, mas que seja participativo e que realize as atividades propostas por seu professor, reflexionando para tornar a formação cada vez mais aberta e mais próxima da ideal.

A reflexão que se pretende despertar é que a relação de ensino-aprendizagem, ou ensinagem, independente do termo que se use, é de que o docente deve renovar constantemente suas metodologias, para que ele se reconheça também sujeito ativo nesse processo, sempre observando e ouvindo seus discentes.

\section{A RELAÇÃO DOCENTE-DISCENTE DURANTE O CURSO DE PEDAGOGIA}

Durante os quatro anos da graduação, nota-se que o curso inicia de maneira mágica, há todo um encantamento, pois, para os calouros, tudo é novidade no universo acadêmico. Os docentes entram em sala, apresentam-se, discorrem sobre seus currículos lattes, e é neste momento que se dá o encantamento. O discente, que está no início de sua caminhada intelectual, em busca do conhecimento científico enxerga aquele ser como o detentor do conhecimento, quase uma divindade.

Pesquisando esta caminhada, ao longo do curso, na fala dos participantes, algumas palavras-chave chamaram atenção, no que diz respeito aos discentes, na relação professor-aluno do curso de Pedagogia: afetividade, autoridade, diálogo, ser professor, e formação docente.

Alguns docentes, quando iniciam seus trabalhos em sala de aula, sabem que a afetividade será sua grande aliada. São aqueles que encantam a turma pela maneira cuidadosa com que preparam seus planos de ensino (planos estes pensados para aquela turma em especial - e não o mesmo plano que perpassa de ano em ano), na flexibilidade dos prazos para entrega 
dos trabalhos (pois sabem que muitos discentes já atuam no mercado de trabalho), no ouvirem o que os discentes já sabem, ou pensam, quanto a determinado assunto ou tema.

Ao falar sobre afetividade, Freire (1996, p.159-60) assim se expressa:

Não é certo, sobretudo do ponto de vista democrático, que serei tão melhor professor quanto mais severo, mais frio, distante e "cinzento" me ponha nas minhas relações com os alunos [...] A afetividade não se acha excluída da cognoscibilidade. O que não posso obviamente permitir é que minha afetividade interfira no cumprimento ético de meu dever de professor no exercício de minha autoridade. Não posso condicionar a avaliação do trabalho escolar de um aluno ao maior ou menor bem-querer que tenha por ele. (destaque do autor).

Apesar de haver docentes que apostam nesta ferramenta, há aqueles que não conseguem manter a ordem em sala de aula, tão pouco a assiduidade, participação e atenção dos discentes, quando estão com a palavra. Surge neste instante outra palavra-chave, a autoridade. Com base ainda nos pensamentos freireanos:

A autoridade sendo um produto da relação professor-aluno não é de todo errada e sim necessária, porém realizada de forma eficaz, conduz o discente a se disciplinar, sendo esse então capaz de adequar seu comportamento a determinadas regras, definidas por ele ou não (FREIRE, 1989, p.38).

Segundo Freire (1989), a autoridade, se usada na medida certa, torna o discente mais disciplinado e uma turma disciplinada contribui, sobremaneira, para a produtividade das aulas. Apesar do perfil autoritário de alguns ao longo do curso, segundo os discentes participantes da pesquisa, muitos docentes deixarão saudades, gostinho de quero mais e estes, pode-se atestar, foram maioria.

O que o aluno nota no fazer docente, neste período, enquanto professor em formação, é que a grande sacada do educador está em estabelecer uma relação com seus alunos baseada no diálogo, outra palavra-chave. Sobre isto, podemos afirmar, amparados em Gadotti, que:

Para pôr em prática o diálogo, o educador não pode colocar-se na posição ingênua de quem se pretende detentor de todo saber; deve, antes, colocar-se na posição humilde de quem sabe que não sabe tudo, reconhecendo que o analfabeto não é um homem "perdido", fora da realidade, mas alguém que tem toda a experiência de vida e por isso também é portador do saber (GADOTTI, 1999 , p.2, destaque do autor).

Corroborando Gadotti, esse respeito que o educador deve ter pelos seus educandos, conquista-se, não se impõe; e o diálogo é o melhor caminho para solucionar problemas. Com isso, fazemos nossas, as palavras de Libâneo (1994, p. 250): 
O professor não apenas transmite uma informação ou faz perguntas, mas também ouve os alunos. Deve dar-lhes atenção e cuidar para que aprendam a expressar-se, a expor opiniões e dar respostas. O trabalho docente nunca é unidirecional. As respostas e as opiniões dos alunos mostram como eles estão reagindo à atuação do professor, às dificuldades que encontram na assimilação dos conhecimentos. Servem também para diagnosticar as causas que dão origem a essas dificuldades.

Compreendemos até aqui que o sucesso que o docente terá ou não na sala de aula, e consequentemente, com a turma que irá trabalhar, trata-se basicamente da concepção do ser professor. Nas palavras de Cunha (1998, p. 70),

A forma de ser professor é um todo e dependente, certamente, da cosmovisão que ele possui. Não sei até que ponto é importante ou possível classificar as atitudes dos professores. Até porque também elas, como fruto da contradição social, nem sempre apresentam formas lineares e totalmente coerentes com uma corrente filosófica. É inegável, porém, que a forma de ser e de agir do professor revela um compromisso. E é esta forma de ser que demonstra mais uma vez a não-neutralidade do ato pedagógico.

Eis a questão, a concepção educacional de cada professor. Algo que será construído ao longo dos anos, durante seu fazer pedagógico. O Curso oportuniza, através de algumas disciplinas, a reflexão quanto às concepções pedagógicas existentes. Cunha (idem, p. 53) afirma que "o conjunto de valores e crenças que dão escopo à performance dos docentes são frutos de sua história e suas experiências de vida dão contornos ao seu desempenho".

Contando com o conhecimento, cabe a cada pedagogo escolher, de forma cuidadosa, qual concepção adotará a partir de então. Preferencialmente, que esta concepção seja baseada na ética, na política e, sobretudo, centrada no aluno.

Por fim, a última palavra-chave que nos restou foi a formação docente. Não por acaso que isto se deu. Segundo Freire (1996 apud SANTOS, 2010, p.32):

O que importa, na formação docente, não é a repetição mecânica do gesto, este ou aquele, ela não caracteriza bons professores, mas a compreensão do valor, do sentimento, das emoções, dos desejos, da insegurança, do medo que, ao ser "educado", vai gerando coragem.

É percebido, até o presente o momento, que não existe um manual de instrução para ser um "bom docente", mas um conjunto de ações e reflexões que devemos fazer na tentativa de buscar o melhor caminho a seguir, nesta longa jornada percorrida por aqueles que militam na Educação. 


\section{APRESENTANDO E JUSTIFICANDO A ESCOLHA DO TEMA}

Pesquisando acerca da seguinte temática: Por que alguns professores são tão amados $e$ outros nem tanto? Encontramos alguns indicadores apontando para considerarmos os diferentes processos sociais no curso de formação de professores, as diferentes propostas curriculares, os métodos, as estratégias e seus procedimentos de ensino e a dificuldade de convivência entre pessoas diferentes. Haveria algo mais?

Para embasamento teórico foram pesquisados alguns autores que discutem a temática relação professor-aluno e formação de professores, como Libâneo (1994), Freire (1989 e 1996), Cunha (1998), Gadotti (1999), Pimenta (2005), entre outros.

Este estudo justifica-se pela necessidade pessoal de buscar uma compreensão do que se estabelece nas relações sociais entre docentes e discentes do curso de Pedagogia da IE/UFMT. Compreender a ambiguidade existente entre a teoria apresentada aos discentes e a prática dos docentes no período de formação. Ao longo dos quatro anos da graduação, foram inúmeras as situações que instigaram os discentes, no sentido de que a prática pedagógica de alguns do quadro de docentes do referido curso no IE nem sempre ia ao encontro das concepções educacionais apresentadas, discutidas e trabalhadas em sala de aula. E, consequentemente, surge a necessidade de verificar se há alguma referência de como se constituir um bom professor.

\subsection{Percurso metodológico}

Com abordagem qualitativa, o estudo descritivo foi realizado no próprio IE, na UFMT, campus Cuiabá/MT. O instrumento utilizado foi a aplicação de um questionário de natureza qualitativa contendo 5 questões abertas e 1 fechada.

Responderam ao questionário, 20 discentes, sendo 14 participantes do $4^{\circ}$ ano, entre eles 13 do sexo feminino e 1 do masculino e 6 discentes do $3^{\circ}$ ano, sendo todos do sexo feminino. Todos os participantes cursavam Pedagogia, no turno matutino.

\subsection{A análise dos dados}

Os participantes foram identificados por números, assegurando o seu anonimato. Perguntados como deveria ser a relação entre docente e discente, as respostas neste questionário foram contundentes, no que diz respeito à interação que deve existir entre estes sujeitos do processo de ensino-aprendizagem: "acima de tudo interação, havendo troca de experiências" (P.1); "uma relação com respeito, harmoniosa, sendo uma relação dialógica" (P.2); “troca de 
conhecimentos" (P.3); "mediada" (P.4); "deve ser uma relação cordial e proveitosa" (P.5); “deve haver reflexão e apoio simultâneo" (P.6); "o docente deve buscar olhar as especificidades dos seus discentes" (P.7); "deve ser uma relação horizontal” (P.8); “de muita confiança” (P.9); "o docente não deve ser arrogante" (P.10); "o sujeito deve ser valorizado" (P.11); "a relação precisa ser interacionista" (P.12); "deve haver comprometimento" (P.13); "precisa ser amigável” (P.14) e, sobretudo, "de companheirismo" (P.15).

A palavra de ordem foi interação. Assim, como a teoria psicogenética de Vygotsky (1984) destaca, o mais importante no desenvolvimento do ser humano é o social, e este desenvolvimento acontece no instante da interação entre o sujeito com o meio. Esse desenvolvimento nada mais é do que a aprendizagem que se dá a partir da interação com o meio, através da experiência e do conhecimento adquirido, sendo internalizado de maneira diferente em cada indivíduo.

Quando o docente deixa de interagir com seus discentes, inibe a mediação entre eles, dificulta o aprendizado e interfere no desenvolvimento pessoal de cada aluno. Fazer a mediação é procurar outras formas de ensinar, em que o mediador deve provocar o movimento, e este vem a ser o que o aluno faz para buscar o conhecimento.

Mais adiante, os participantes foram questionados se, durante o curso de graduação, houvera alguma referência sobre a relação professor-aluno; se a resposta fosse positiva, ele poderia responder quando e onde. As respostas apresentam-se conforme Quadro 1 abaixo:

Quadro 1- Narrativas dos participantes sobre a relação professor-aluno durante o curso.

\begin{tabular}{|c|c|}
\hline Respostas & Participantes \\
\hline $\begin{array}{l}\text { Nas disciplinas de Avaliação, Currículo, Didática, Psicologia, } \\
\text { Matemática, Estágio e Linguagem IV foi discutido este assunto. }\end{array}$ & $\begin{array}{l}\text { Participantes } \mathrm{n}^{\mathrm{o}}: 1,12,14,15,16 \text {, } \\
19\end{array}$ \\
\hline 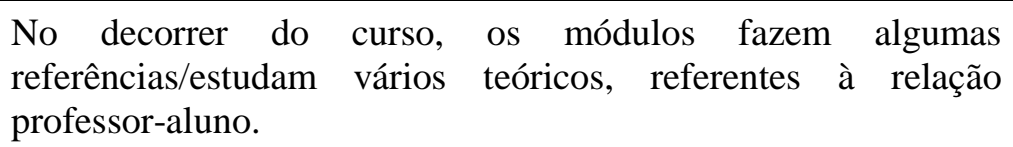 & Participantes $\mathrm{n}^{\circ}: 2,11,13$ \\
\hline $\begin{array}{l}\text { Em um congresso percebi a importância da relação docente- } \\
\text { discente. }\end{array}$ & Participante $n^{\circ} 18$ \\
\hline $\begin{array}{l}\text { É sempre falado sobre a relação docente-discente, mas às vezes } \\
\text { não acontece na prática. Alguns professores são autoritários e } \\
\text { coercitivos. }\end{array}$ & Participante $n^{\circ}: 6$ \\
\hline $\begin{array}{l}\text { Um docente fez críticas aos discentes de forma agressiva, e outro } \\
\text { fez julgamento do aluno sem conhecê-lo. }\end{array}$ & Participantes $n^{\circ}: 4$ e 8 \\
\hline $\begin{array}{l}\text { Docentes que não suportam ser confrontados / Não consideram } \\
\text { os esforços dos seus alunos. }\end{array}$ & Participantes $n^{\text {o: }} 3$ e 10 \\
\hline $\begin{array}{l}\text { Ausência de diálogos em sala para discutir a relação professor- } \\
\text { aluno. }\end{array}$ & Participante $\mathrm{n}^{\circ} 7$ \\
\hline
\end{tabular}




\begin{tabular}{|l|c|}
\hline \multicolumn{1}{|c|}{ Respostas } & Participantes \\
\hline Não respondeu / Não me recordo. & Participantes n ${ }^{\circ}: 5,9,17$ \\
\hline
\end{tabular}

Fonte: Dados coletados pela autora.

O que se percebe, ao observar as respostas dos participantes, é que houve referências positivas de $50 \%$, negativas de $30 \%$ e $20 \%$ abstiveram-se da resposta. A maioria fez, de certo modo, uma boa avaliação, quanto a esta questão durante o curso. No entanto, ao mesmo tempo, fica um alerta, pois, em se tratando de curso de formação de professores, 6 participantes discorreram quanto a incidentes no decorrer do curso, utilizando-se deste espaço para fazer uma espécie de desabafo no que tange à relação docente-discente.

A respeito dos conflitos em meio escolar, alguns pesquisadores como Araújo (1996), La Taille (1996; 1998), Leite (2008), Martinez Zampa (2005) e Vinha (1999) apontam que, em meio ao universo escolar, é comum a existência de fatores que contribuam para o surgimento de conflitos e que, na maioria das vezes, acabam trazendo prejuízos a todos os envolvidos.

Segundo La Taille (1996, 1998), Araújo (1996) e Vinha (1999) (apud LEITE; LÖHR, 2012), baseados na perspectiva piagetiana defendem que:

O desrespeito às normas nem sempre é problemático, podendo ser sinal de autonomia, significando resistência às imposições e ao autoritarismo. Vinha (1999) ainda reforça que a teoria construtivista compreende os conflitos como oportunidades para trabalhar valores e regras. Esses conflitos [...] "dão-nos pistas sobre o que as crianças e jovens precisam aprender." Ou seja, na perspectiva dos autores citados, o conflito professor-aluno é inerente ao processo de desenvolvimento e pode contribuir para a formação dos jovens (p. 586).

Em meio às respostas que evidenciam situação de conflito, há a de uma participante mencionando que, nos três primeiros anos da graduação, algumas disciplinas mencionam de forma sucinta esta questão, ou seja, há pouca discussão quanto a esta temática, com exceção do $4^{\circ}$ ano, em função da proximidade com o Estágio. Estariam os docentes, responsáveis pela formação dos futuros professores, de fato inseridos no processo que a autora Pimenta (2005, p.20) trata de "reflexão na ação"?

Mais adiante perguntamos quais seriam as características que um profissional da educação deveria ter para ser reconhecido como um(a) bom(a) professor(a). Segundo nossos participantes essas características são o diálogo, o domínio do conteúdo e a mediação do conhecimento. Abaixo, no Quadro 2, temos as respostas dos participantes: 
Quadro 2 - Caracterizadores de um bom docente.

\begin{tabular}{|l|l|}
\hline Características agrupadas em categorias & Participantes \\
\hline Ético/Capacitado/Orientador. & 1 \\
\hline Dominar o conteúdo. & 3,4 e 20 \\
\hline $\begin{array}{l}\text { Mediador do Conhecimento/ Comprometido/ Reflexivo/ Atencioso/ } \\
\text { Pesquisador/Amigo/ Paciente/ Amar lecionar. }\end{array}$ & $5,6,7,13$ e 15 \\
\hline Apresentar facilidade para o diálogo. & $\begin{array}{l}2,12,16,17,18,19 \\
\text { e } 20\end{array}$ \\
\hline Contar com estratégias variadas de ensino. & 8 \\
\hline Preocupar-se com o aprendizado do aluno. & 9 e 14 \\
\hline Posicionar-se politicamente/Militante. & 10 \\
\hline Despertar no aluno o interesse em aprender. & 11 \\
\hline
\end{tabular}

Fonte: Dados coletados pela autora.

Perguntados sobre quais seriam as principais ações a desenvolver para que fossem reconhecidos por seus alunos como bons professores, os graduandos que atuam (ou pretendem atuar,) na educação, em sua maioria, elencaram atitudes tais como estabelecer uma relação dialógica com os alunos, ser atencioso e comprometido, pautar o trabalho no conhecimento, ser um professor pesquisador, trabalhar em consonância com o Projeto Político Pedagógico (PPP) da instituição, ser dedicado, utilizar métodos eficientes de aprendizagem, fazer o aluno ser participativo nas aulas, ser militante, respeitar o aluno, ser paciente e despertar nele o desejo em aprender. Um dos participantes respondeu que não atua na docência e não pretende fazê-lo e outro não respondeu.

Ressalte-se que a característica de ser um professor comprometido foi lembrada por alguns participantes (P.13, P.6 e P.17), e aqui recordamos que o filósofo Comenius (2001), ainda no século XVII, já destacava que o professor deve ser comprometido e despertar em seus alunos o gosto pelo aprender.

Outra resposta que merece destaque foi a característica do posicionamento político, mencionada pelo P.10. Entendemos que educação não é alcançada num passe de mágica, mas sim, é resultado das escolhas políticas que fazemos, ou seja, não existe espaço para a neutralidade política no ato pedagógico. 
Em outra pergunta, foi questionado aos entrevistados se/até que ponto um bom relacionamento entre docente e discente interferiria no processo de ensino-aprendizagem e foilhes pedido que as respostas fossem justificadas.

Os que responderam que essa relação interfere, alegaram: P.1 - “considerar a avaliação informal no processo de aprendizagem do aluno"; outra justificativa defendeu que um bom relacionamento entre os protagonistas dessa relação deveria ser: P.3 - "pautado no respeito mútuo"; P.4 /P.10/P.13/P.14 - "se existir um bom relacionamento, haverá aprendizado"; P.5 "fundamental na perspectiva sociointeracionista"; P.7 - "professor-exemplo para o aluno"; P.8/P.11 - "o rendimento do aluno cairá, se não houver um bom relacionamento"; P.9/P.12 "quando o aluno gosta do professor, ele se interessa pelo conteúdo"; P.6/P.16/P.17/P.19/P.20 "quando há diálogo entre professor e o aluno", ou seja, quando a relação estabelecida seja pautada na conversa, onde não apenas o docente é detentor do conhecimento; "o processo de aprendizagem é motivador" e P.18 - "se houver um bom relacionamento, o professor não se importará com o conteúdo". Os participantes que afirmaram não interferir, justificaram: P.15 "toda relação tem que ter equilíbrio e bom-senso", na fala do entrevistado apesar de um bom relacionamento não interferir, o significado de uma relação pautada no bom senso seria uma relação onde os sujeitos tivessem a oportunidade de se expressar livremente e sua opinião fosse respeitada, mesmo quando diferente e, por fim, P.2 - “o bom relacionamento facilita, mas não interfere".

O que se observa nesta questão é que $90 \%$ dos participantes disseram que um bom relacionamento entre docente-discente interfere neste processo. Apenas $10 \%$ responderam que não, pois facilita um bom entendimento entre os sujeitos do processo de ensino-aprendizagem, mas não interfere. Na questão seguinte, foi solicitada a enumeração de 1 a 4, de acordo com o grau de importância de cada item para a relação professor-aluno, conforme demonstra o Gráfico 1, que segue: 
Gráfico 1- Importância na relação docente-discente

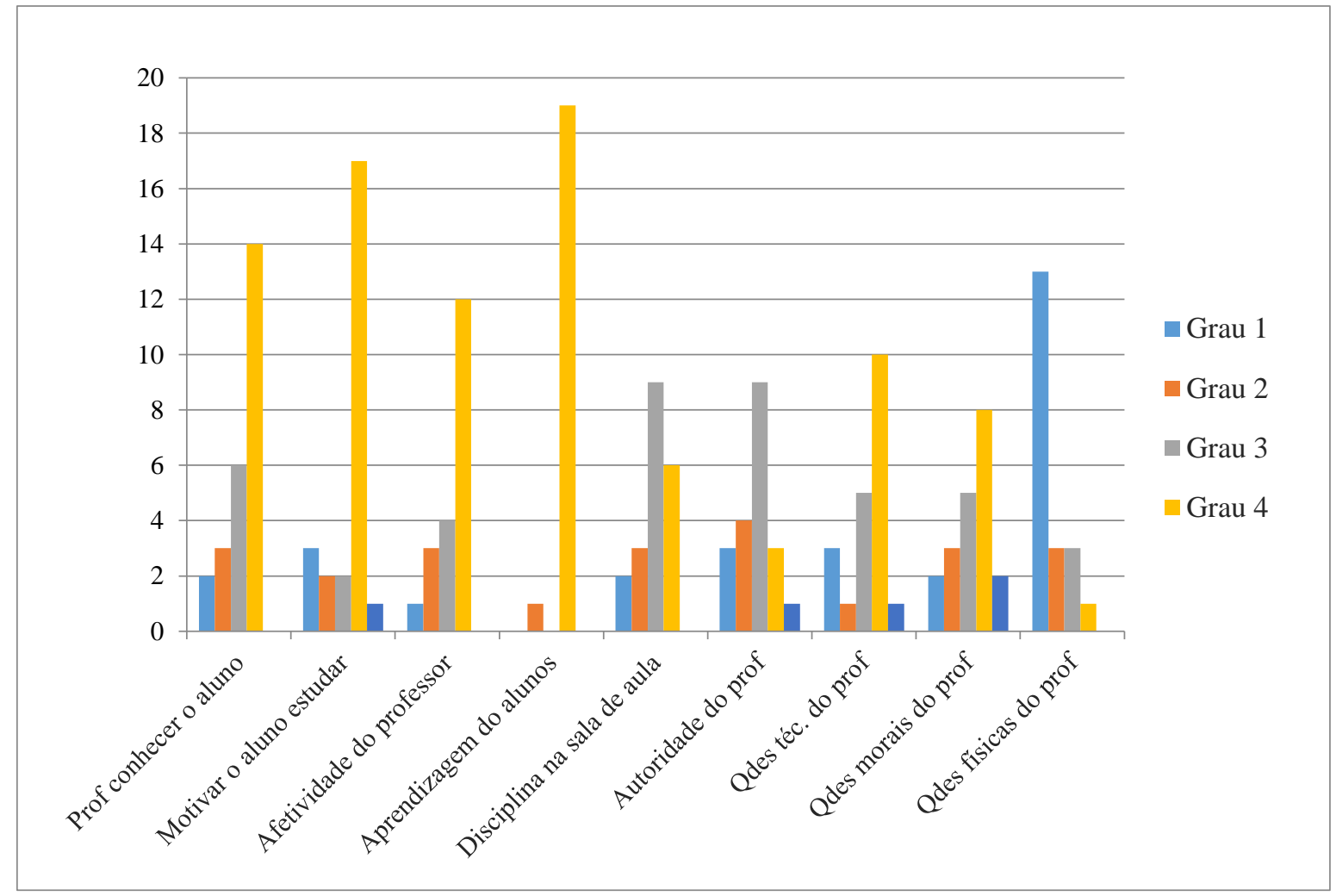

Fonte: Dados coletados pela autora.

Com base nos dados acima, segundo os participantes, o item que tem o maior grau de importância na relação professor-aluno é aprendizagem do aluno, seguido por motivar o aluno para estudar e em $3^{\circ}$ lugar, professor conhecer o aluno.

O item qualidades físicas do professor foi o que teve mais voto no grau 1, ou seja, os discentes do Curso de Pedagogia acreditam que este item não apresenta relevância. Em $4^{\circ}$ lugar ficou afetividade do professor; em $5^{\circ}$ lugar, o item qualidades técnicas do professor. Em $6^{\circ}$, qualidades morais do professor; em $7^{\circ}$ lugar, disciplina em sala de aula, seguido de autoridade do professor e, por último, em $8^{\circ}$ lugar, o item qualidades físicas do professor.

Analisando o Gráfico 1 anterior, evidencia-se que, para os futuros pedagogos, a aprendizagem do aluno é fator de grande importância nesta relação, o que confere com os resultados obtidos anteriormente, em que a relação dialógica foi bastante mencionada na questão aberta, de número 4, do questionário apresentado.

Outro fato curioso é que os discentes dão maior grau de importância às qualidades técnicas do professor do que para a disciplina na sala de aula e mesmo à autoridade do professor. Esse dado surpreende, pois, a maioria dos participantes é formada por alunos concluintes do curso. Após o término do Estágio Supervisionado (Período da Regência) eram comuns alguns 
comentários a respeito da dificuldade em controlar a turma e manter a disciplina em sala, características em equidade aos itens: a autoridade do professor e a disciplina em sala de aula.

Gráfico 2 - Questão de número 07 do questionário

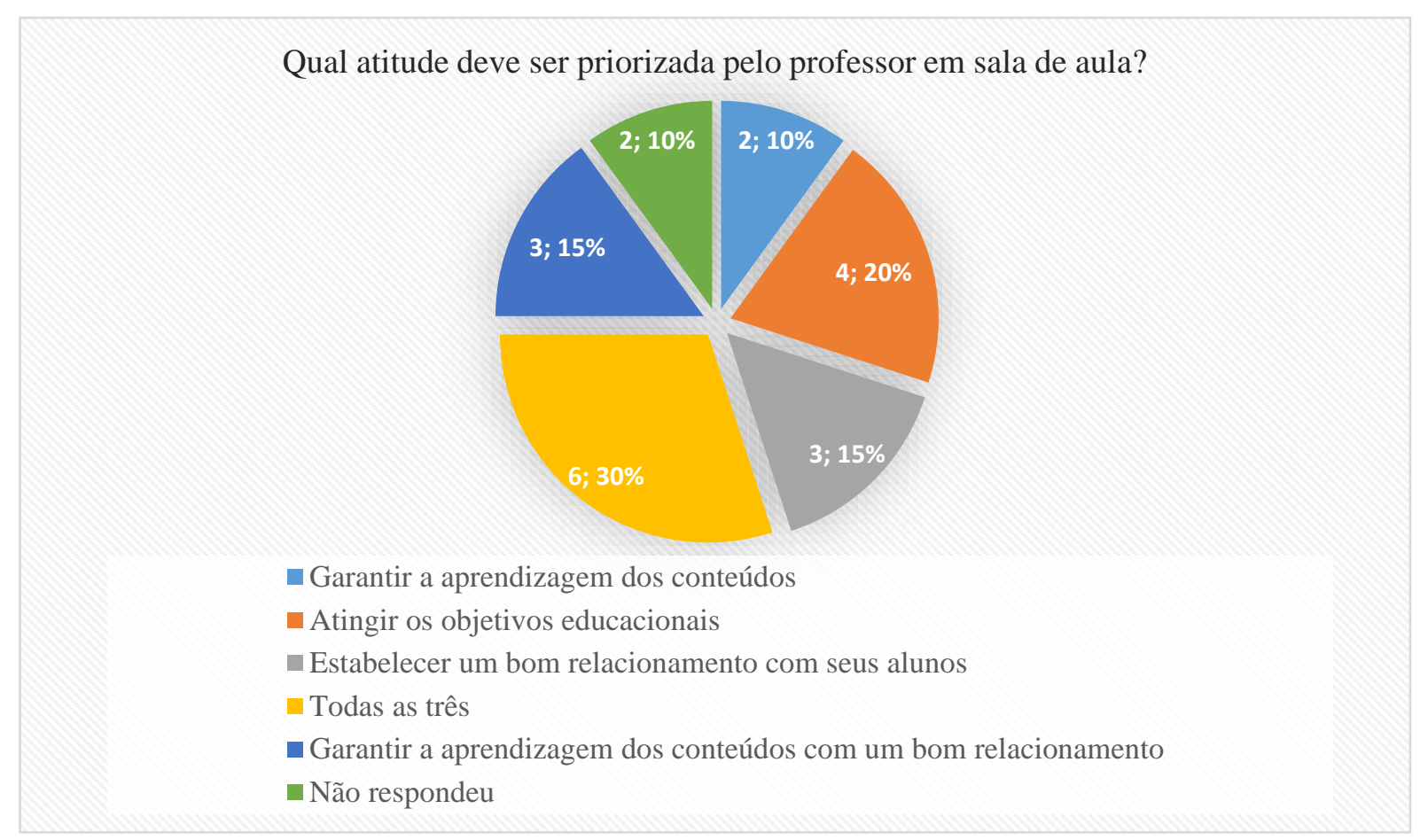

Fonte: Dados coletados pela autora.

Com $60 \%$, a atitude que o professor deve priorizar seria a somatória das três atitudes apresentadas: garantir a aprendizagem dos conteúdos, atingir os objetivos educacionais e estabelecer um bom relacionamento com seus alunos receberam seis votos; com 20\%, a segunda atitude mais votada foi somente atingir os objetivos educacionais, que recebeu 4 votos; em $3^{\circ}$ lugar com $15 \%$ ficaram empatados estabelecer um bom relacionamento com seus alunos e garantir a aprendizagem dos conteúdos com um bom relacionamento, ambos receberam três votos; em último lugar deu empate entre garantir a aprendizagem dos conteúdos e não respondeu, totalizando dois votos para cada atitude.

A criatividade dos participantes na escolha pela somatória das três atitudes apresentadas na questão de número sete enuncia que o(a) pedagogo(a) vem refletindo e concluindo que, para obtermos uma educação de qualidade, é preciso que se tenha clareza dos objetivos que nós, educadores atuantes ou não, precisamos alcançar, sempre com foco no aluno, garantindo sua aprendizagem e para tanto, estabelecer um bom relacionamento com nossos alunos torna-se indispensável. 


\section{CONSIDERAÇÕES FINAIS}

Finalizando o estudo realizado, pode-se afirmar que o curso de Pedagogia do IE/UFMT vem contribuindo para formação do bom docente, pois a maioria dos entrevistados fez uma boa avaliação da relação professor-aluno no decorrer da graduação.

O estudo, sobretudo, propiciou aos discentes um espaço para que os mesmos pudessem expor quais seriam as concepções de bom docente e mau docente. Os entrevistados apresentaram a ideia de que o bom docente é o professor que possui um conjunto de características, tais como: ser capaz de manter uma relação pautada no diálogo, dominar o conteúdo que ensina, e acima de tudo, ele deve ser o mediador do conhecimento. E o mau docente é aquele que assume posição autoritária na condução de sua aula, fato infelizmente, ainda recorrente no curso de formação de professores.

Ressaltamos que não existe uma receita pronta; quando se trata de relações sociais, os resultados reverberam por longo prazo. Um bom relacionamento entre docente-discente deve ser pautado no diálogo, respeito mútuo, comprometimento, conhecimento, no estudo de novos métodos e técnicas de ensino cada vez mais pensados em estimular e facilitar o processo de ensino-aprendizagem. E esta via precisa ser de mão dupla, pois o discente também precisa fazer sua parte, sendo um aluno participativo, demonstrando interesse por aprender, respeitando os docentes e, sobretudo, compreendendo que educador e educando são sujeitos deste processo, crescem juntos.

O que fica é a compreensão de que os educadores devem estar em constante processo de formação, assim como em constante reflexão a partir do subproduto da formação teórica e da compreensão do trabalho docente. O processo não se encerra com a obtenção do diploma, certificados. Ele é fruto de uma formação continuada que nunca se encerra. Conscientes de que devemos ser lembrados não apenas como bons docentes, mas acima de tudo, enquanto professores que a nossa ação docente não se afaste dos teóricos que optamos por trabalhar. Docentes comprometidos em desenvolver o ser humano, preparando-o para o exercício da cidadania e qualificando-o para o trabalho.

\section{REFERÊNCIAS}

ARAÚJO, Ulisses Ferreira. Moralidade e indisciplina: uma leitura possível a partir do referencial piagetiano. In: AQUINO, Júlio R. G. (Org.). Indisciplina na escola: alternativas teóricas e práticas. 7. ed., São Paulo: Summus, 1996. p. 103-116. 
CUNHA, Maria Isabel da. O professor universitário na transição de paradigmas. Campinas: Papirus, 1998.

BOURDIEU, Pierre. Escritos de educação. Petrópolis: Vozes, 1998.

DURKEIM, Émile. Educação e sociologia. Rio de Janeiro: Vozes, 2013.

FREIRE, Paulo. Pedagogia da autonomia: saberes necessários à prática educativa. 35 ed. São Paulo: Paz e Terra, 1996.

Disciplina na escola: autoridade versus autoritarismo. São Paulo: EPU, 1989.

GADOTTI, Moacir. Convite à leitura de Paulo Freire. São Paulo: Scipione, 1999.

IOHANNIS, Amos Comenius. Didática Magna. E-books Brasil. Fundação Calouste Gulbenkian. Copyright: 2001.

LA TAILLE, Yves de. A indisciplina e o sentimento de vergonha: indisciplina na escola. São Paulo: Summus, 1996.

Limites: três dimensões educacionais. São Paulo: Ática, 1998.

LEITE, Nádia M. B. Síndrome de Burnout e relações sociais no trabalho. 2008. $168 \mathrm{f}$. Dissertação (Mestrado em Psicologia) - Universidade de Brasília, Brasília, 2008.

LEITE, Célio Rodrigues; LÖHR, Suzane Schmidlin. Conflitos professor-aluno: uma proposta de intervenção. Rev. Diálogo Educ., Curitiba, v. 12, n. 36, p. 575-590, maio/ago. 2012.

Disponível em: <http://www.redalyc.org/articulo.oa?id=189123663014>. Acesso em: 29 jan. 2015.

LIBÂNEO, José Carlos. Didática. São Paulo: Cortez, 1994.

LIBÂNEO, José Carlos. O ensino de graduação na universidade - A aula universitária. Disponível em: 〈http://www.ucg.br/site_docente/Edu/libaneo/pdf/ensino.pdf〉. Acesso em: 24 out. 2014.

MARTINEZ ZAMPA, Daniel F. Mediación educativa y resolución de conflictos: modelos de implementación. Buenos Aires: Novedades Educativas, 2005.

PIMENTA, Selma Garrido; ANASTASIOU, Léa das Graças Camargos. Docência no Ensino Superior. 5.ed. São Paulo: Cortez, 2005.

PIMENTA, Selma Garrido (Org.). Professor reflexivo no Brasil: gênese e crítica de um conceito. 3. ed. São Paulo: Cortez, 2005.

Docência no Ensino Superior. 5.ed. São Paulo: Cortez, 2005.

ROUSSEAU, Jean-Jacques. Rousseau e as Relações Internacionais. São Paulo: Imprensa Oficial do Estado, 2003, 316 p. 
SANTOS, Marcus Vinícius Paulino dos. A caracterização do "bom professor" conforme a visão dos alunos de uma escola pública do Estado de São Paulo. Trabalho de Conclusão de Curso (Graduação em Ciências Biológicas) - Universidade Presbiteriana Mackenzie, 2010. Disponível em:

<http://www.mackenzie.br/fileadmin/Graduacao/CCBS/Cursos/Ciencias_Biologicas/1o_201/ Biblioteca_TCC_Lic/2010/2o_2010/MARCUS_VINICIUS_PAULINO.pdf >. Acesso em: 24 out. 2014.

SIQUEIRA, Denise de Cássia Trevisan. Relação professor-aluno: uma revisão crítica. Disponível em: 〈http://www.usjt.br/proex/arquivos/produtos_academicos/97_33.pdf>. Acesso em: 24 out. 2014.

VIGOTSKY, Lev S. A formação social da mente. 3. ed. São Paulo: Martins Fontes, 1984.

VINHA, Telma P. Valores morais em construção. Revista AMAE-Educando, Belo Horizonte, n. 285, p. 6-12, 1999.

\section{SOBRE OS AUTORES}

Viviane Salarolli de Souza Silva é pedagoga pela Universidade Federal de Mato Grosso (UFMT), mestranda em Educação no Programa de Pós-Graduação em Educação da Universidade Federal de Mato Grosso (UFMT) e pesquisadora do Grupo de Estudos e Pesquisas sobre Corporeidade e Ludicidade (GEPCOL).

E-mail: vivianesalarolli@gmail.com

Cleomar Ferreira Gomes é Doutor em Educação pela Universidade de São Paulo (USP), Professor Associado da Universidade Federal de Mato Grosso (UFMT) e líder do Grupo de Estudos e Pesquisas sobre Corporeidade e Ludicidade (GEPCOL).

E-mail: gomescleo.cg@gmail.com 